\title{
In-hospital Initiation of PCSK9 Inhibitor and Short- term Lipid Profile Alteration, as well as In-hospital Mortality and Readmission Rate in Patients with Acute Myocardial Infarction
}

Jianqing She ( $\boldsymbol{\sim}$ jianqingshe@mail.xjtu.edu.cn )

First Affiliated Hospital of Xi'an Jiaotong University

Bowen Lou

First Affiliated Hospital of Xi'an Jiaotong University

Hui Liu

First Affiliated Hospital of Xi'an Jiaotong University

Yongbai Luo

First Affiliated Hospital of Xi'an Jiaotong University

Gulinigaer Tuerhong Jiang

First Affiliated Hospital of Xi'an Jiaotong University

Haoyu Wu

First Affiliated Hospital of Xi'an Jiaotong University

Chen Wang

First Affiliated Hospital of Xi'an Jiaotong University

\section{Yue Wu}

First Affiliated Hospital of Xi'an Jiaotong University

\section{Bo Zhou}

First Affiliated Hospital of Xi'an Jiaotong University

\section{Zuyi Yuan}

First Affiliated Hospital of Xi'an Jiaotong University

Junhui Liu

First Affiliated Hospital of Xi'an Jiaotong University

\section{Research Article}

Keywords: PSCK9i, Statin, LDL, AMI

Posted Date: February 16th, 2022

DOI: https://doi.org/10.21203/rs.3.rs-1329394/v1 
License: (c) (i) This work is licensed under a Creative Commons Attribution 4.0 International License. Read Full License 


\section{Abstract}

\section{Background}

Proprotein convertase subtilisin/kexin type 9 (PCSK9) inhibitors have been shown to improve cardiovascular outcomes when added to conventional statin therapy. This study aims to investigate the efficacy and safety of in-hospital initiation of PCSK9 inhibitor among patients with acute myocardial infarction(AMI) based on real-world experience.

\section{Methods and Results}

Data were collected from the Biobank of the First Affiliated Hospital of Xi'an Jiaotong University between January 2016 and December 2020. 7556 AMI patients were screened for eligibility. Propensity Score Match(PSM) was employed and covariates were age, sex, admission blood pressure and lipid profiles. Eligible participants were (1) propensity-matched 1:2:2 of Statin plus Evolocumab (dual therapy) vs. Statin vs. Statin plus Ezetimibe. 95 Statin plus Evolocumab users achieved significant decreased LDL level $\left(0.92 \pm 0.62 \mathrm{mmol} / \mathrm{L}\right.$ in the $1^{\text {st }}$ month and $1.17 \pm 0.73$ in the $3^{\text {rd }}$ month) and a promising attainment rate of $\operatorname{LDL}\left(79.5 \%\right.$ in $1^{\text {st }}$ month and $80.0 \%$ in the $3^{\text {rd }}$ month ) as compared to the other two groups. (2) propensity-matched 1:2:2 of Statin plus Ezetimibe Evolocumab (triple therapy) vs. Statin vs. Statin plus Ezetimibe. Similarly, 75 triple medication users achieved significantly decreased LDL levels and a promising attainment rate of LDL as compared to the other two groups. In-hospital mortality, readmission rate within 3 months were then analyzed and decreased readmission rate was observed through PCSK9i therapy.

\section{Conclusions}

Based on the present single-centre real-world PSM-adjusted study, PCSK9i has been effective in shortterm lipid control among AMI patients. The long-term effectiveness for reducing major cardiovascular events among AMI patients based on real-world experience remains to be explored.

Trial registration: The study was registered at ClinicalTrials.gov, Unique Protocol ID: 82100477-1.

\section{Introduction}

Due to the high rate of mortality and morbidity, acute myocardial infarction (AMI) plays as one of the leading health-threatening problems worldwide ${ }^{1,2,3}$. Apart from acute reperfusion therapy including fibrinolytic drugs, percutaneous intervention( $\mathrm{PCl}$ ), and coronary artery bypass graft surgery, secondary prevention medication is still the foundation for AMI patients. Especially, lipid lowering drugs treatments are cornerstones for acute and chronic management in AMI patients ${ }^{4-6}$.

The advent of Proprotein Convertase Subtilisin-Kexin Type 9(PCSK9) has brought a breakthrough in the treatment of atherosclerotic disease. PCSK9 is a secreted serine protease synthesized by the liver, which 
can bind to and degrade LDL receptors, thereby reducing the clearance of serum LDL $^{7}$. It has been shown by previous clinical studies that patients with the atherosclerotic disease still have poor LDL-C level control under the conventional statin and ezetimibe treatment. One observational study has indicated that after receiving statin treatment for at least 3 months, the standard rate of LDL-C in patients with very high-risk dyslipidemia is only $23.9 \%^{8}$. Thus, the recommendation of LDL target values for ASCVD patients tend to be lower and lower; and currently, for patients at very high risk, LDL reduction of $\geq 50 \%$ from baseline and an LDL goal of $<1.4 \mathrm{mmol} / \mathrm{L}(<55 \mathrm{mg} / \mathrm{dL})$ are suggested ${ }^{9,10}$. A growing number of clinical studies of PCSK9i have proved that high-risk atherosclerosis patients can achieve satisfied blood lipid (especially LDL-C) control by combining PCSK9i on the basis of statin treatment, thus further reducing the risk of myocardial infarction, stroke and other events ${ }^{11-13}$.

However, most of the previous studies discussing the clinical effectiveness of PCSK9i were based on chronic lipids management. In addition, according to contemporary guidelines ${ }^{14,15}$, PCSKi should be initiated when the initiation of statin and ezetimibe has not met the targeted LDL-C levels. Thus, few studies are focusing on the effectiveness, safety and cardiovascular benefits of PCSK9i on LDL-C management when initiated during the acute phase of cardiovascular events. In the latest Chinese consensus on dyslipidaemia management in patients with high-risk atherosclerosis disease ${ }^{16}$, it is recommended that the individualized lipid-lowering therapy should be selected according to the patient's baseline LDL-C level and the expected reduction range of the lipid-lowering regime. As a result, some AMI patients with high baseline LDL-C levels might opt to receive the combined treatment of statins and PCSK9i in the early stage of AMI onset. Whereas, clinical evidence for the efficacy and safety of this treatment regime that combined PCSKi and statin could be initiated during the acute phase of AMI for high-risk patients with high baseline LDL-C levels based on real-world experience are still limited.

Therefore, this study aims to investigate the efficacy and safety of in-hospital initiation of PCSK9i in patients with AMI based on real-world experience. Through this single-centre real-world study, in-hospital initiation of PCSK9i has been effective in short-term lipid control among AMI patients. The long-term effectiveness for reducing major cardiovascular events remains to be explored.

\section{Methods And Results}

\section{Study design and Clinical data collection}

This was a single-centre, retrospective cohort study. 7556 consecutive patients admitted to the cardiology department of the First Affiliated Hospital of Xi'an Jiaotong University for AMI between January 2016 and December 2020 were enrolled. The inclusion criteria were confirmed admission diagnosis of AMI and were defined based on the universal definition criteria by the American Cardiology College ${ }^{2}$. The exclusion criteria were: (1) severe noncardiac disease with an expected survival of less than 1 year and unwillingness to participate; (2) patients over the age of 80 years or living far away from the hospital's 
catchment area. A patient could only be included once. In hospital, PCSK9i was initiated according to the Chinese consensus on dyslipidaemia management in patients with high-risk atherosclerosis disease ${ }^{16}$.

The medical records of the patients were collected from the Biobank of the First Affiliated Hospital of Xi'an Jiaotong University, which contains the identified data derived from raw medical records, information about patients' detailed medical histories, present medication, biochemical and echocardiography results. Follow-up information, including in-hospital mortality, readmission rate as well as short-term lipid profile alteration were obtained via biobank, telephone and questionnaires by the general practitioner (GP). Written informed consent was obtained from all study participants, with ethnic committee approval at the First Affiliated Hospital of Xi'an Jiaotong University. The study was registered at ClinicalTrials.gov, Unique Protocol ID: 82100477-1.

\section{Study Cohorts and Treatments}

Participants were allocated into four groups according to different lipid-lowering strategies: 1). Statin, 2).Statin plus Ezetimibe, 3).Statin plus Evolocumab and 4). Statin plus Ezetimibe plus Evolocumab, contingent on whether they began Evolocumab during hospitalization. Patients were initiated with Evolocumab(140 mg per two weeks, subcutaneous injection) during hospitalization either due to extremely high LDL level and/or large area myocardial infarction based on the Chinese consensus on dyslipidaemia management in patients with high-risk atherosclerosis disease ${ }^{16}$. The use of Statin(20mg atorvastatin or $10 \mathrm{mg}$ rosuvastatin per day) or Statin plus Ezetimibe(10mg per day) therapy was based on the present guidelines for the treatment of $\mathrm{AMI}^{17}$.

\section{Propensity Score Match}

Because patients receiving Statin, Ezetimibe and Evolocumab according to their admission LDL level and varied a lot on baseline characters, Propensity Score Match(PSM) was employed and covariates were age, sex, admission blood pressure and lipid profiles. All eligible participants were (1) propensitymatched 1:2:2 of Statin plus Evolocumab vs. Statin vs. Statin plus Ezetimibe, and (2) propensity-matched 1:2:2 of Statin plus Ezetimibe Evolocumab vs. Statin vs. Statin plus Ezetimibe. The propensity score was performed by R 3.6.0 and package Matchlt and calculated using the values of the covariates.

\section{Statistics}

All statistical analyses were performed by using SPSS for Mac 22.0 (SPSS Inc, Chicago, IL), Graphpad 9.0 Prism (GraphPad Software San Diego, CA) or R 3.6.0. Data were presented as frequencies or percentages for categorical variables and mean $\pm S D$ for continuous variables, unless otherwise indicated. Simple t-test was used to compare continuous variables which are in the normal distribution. Mann-Whitney $U$ test was used to compare continuous variables which do not conform to the normal distribution. $\chi 2$ test was used 
to compare categorical variables. One-way ANOVA was used to compare continuous variables of three or more independent (unrelated) groups. A value of $\mathrm{P}<0.05$ was considered statistically significant.

\section{Results}

\section{Study Cohort}

A total of 7556 AMI patients from the biobank database between January 2016 and December 2020 were screened for eligibility. After excluding those without revascularization or Statin based therapy, the remaining 5802 Statin users, 801 Statin plus Ezetimibe users and 170 Statin plus Evolocumab users (including 95 users without and 75 users with Ezetimibe), were selected for this study. Then, $1^{\text {st }}$ and 3 rdmonth follow-up data were collected and analysed, including in-hospital mortality, readmission rate and lipid profiles(Fig.1).

As admission LDL level and crowd size vary among different lipid-lowering strategy groups, propensity score match(PSM) was performed for further analysis. $1^{\text {st }}$ PSM based on Statin plus Evolocumab therapy and of these, 95 users were successfully matched with 190 Statin users and 190 Statin plus Ezetimibe users respectively. $2^{\text {nd }}$ PSM based on Statin plus Ezetimibe plus Evolocumab(triple) therapy and of these, 75 users were successfully matched with 150 Statin users and 150 Statin plus Ezetimibe users respectively. The matched groups were well-balanced in demographic and clinical characteristics(Appendix Table1 and 2, appendix Fig1 and 2).

\section{Baseline Characteristics and short-term follow-up in the whole cohort.}

In the whole cohort, the mean ages were $62.90 \pm 11.91,58.73 \pm 12.16,57.72 \pm 11.07$ and

$54.38 \pm 11.77$ years among Statin, Statin plus Ezetimibe, Statin plus Evolocumab and triple therapy groups. The admission LDL was $2.25 \pm 0.74,2.95 \pm 1.03,3.24 \pm 0.98$ and $3.90 \pm 1.45 \mathrm{mmol} / \mathrm{L}$ respectively(Table.1), which is also inconsistent with the basic strategy that higher LDL level requires intensive lipid-lowering therapy in AMI patients. According to 2019 ESC/EAS Guidelines for the management of dyslipidaemias ${ }^{9}$, for patients at very high cardiovascular risk, LDL reduction of $\geq 50 \%$ from baseline and an LDL goal of $<1.4$ $\mathrm{mmol} / \mathrm{L}(<55 \mathrm{mg} / \mathrm{dL})$ are recommended. We further analysed the control situation of $\mathrm{LDL}(<1.4 \mathrm{mmol} / \mathrm{L})$ among each group. On admission, the target rate was $11.8 \%, 4.0 \%, 3.2 \%$ and $1.3 \%$ among each group; In the $1^{\text {st }}$ month follow-up, around $37.0 \%, 28.8 \%, 79.5 \%$ and $55.3 \%$ of the whole patients reached treatment goal among each group and after 3month, $40.6 \%, 29.3 \%, 80.0 \%$ and $43.8 \%$ respectively(Table 1 ). Despite higher LDL levels at admission, AMI patients achieved a promising control rate in the short-term PCSK9i treatment.

Around $1.9 \%$ AMI patients died with Statin alone therapy and $0.7 \%, 0.8 \%, 0.0 \%$ among Statin plus Ezetimibe, Evolocumab dual and triple group during the 3month follow-up. The readmission rate was 


\section{Statin plus Evolocumab therapy(dual therapy) based PSM analysis}

95 Statin plus Evolocumab users, 190 Statin users and 190 Statin plus Ezetimibe users were well matched for this PSM analysis. The mean age was 59.42 $\pm 11.66,58.62 \pm 12.73$ and $58.53 \pm 10.63$ among each group and the admission LDL was 3.11 $\pm 1.02,3.24 \pm 1.13$, and 3.24 $\pm 0.98 \mathrm{mmol} / \mathrm{L}$ respectively after PSM adjustments.

In admission, 0.5\%, 2.1\% and 3.2\% AMI patients reached target LDL level among Statin, Statin plus Ezetimibe, Statin plus Evolocumab group. In the $1^{\text {st }}$ month follow-up, the target rate was $31.0 \%, 21.3 \%$, 79.5\% and $29.4 \%, 21.4 \%, 80.0 \%$ after 3month respectively(Fig3.A). The mean LDL level was significantly decreased in Statin plus Evolocumab users compared to other two groups, with 0.92 $\pm 0.62,1.58 \pm 0.44$, $1.96 \pm 0.82 \mathrm{mmol} / \mathrm{L}$ in $1^{\text {st }}$ month and $1.17 \pm 0.73,1.61 \pm 0.49,2.10 \pm 0.82$ month in the $3^{\text {rd }}$ month. (Table2 and Fig3.B). Also, a similar trend was observed in ApoB level, with 0.39 $\pm 0.20,0.64 \pm 0.16, \quad 0.70 \pm 0.22$ $\mathrm{g} / \mathrm{L}$ in $1^{\text {st }}$ month and $0.46 \pm 0.20,0.59 \pm 0.15,0.75 \pm 0.22 \mathrm{~g} / \mathrm{L}$ in the $3^{\text {rd }}$ month follow-up respectively. Around 4.0\% AMI patients were re-hospitalized with Statin plus Evolocumab therapy, and 11.6\%,10.5\% readmission rate in the other two groups during the short-term follow-up.

\section{Statin plus Ezetimibe plus Evolocumab therapy(triple therapy) based PSM analysis}

In the 7556 AMI patients, 75 patients received triple therapy (Statin plus Ezetimibe plus Evolocumab) and were well matched with 150 Statin users and 150 Statin plus Ezetimibe users. The mean age was $52.59 \pm 11.92,53.57 \pm 11.29$ and $53.67 \pm 11.86$ among each group and the admission LDL was $3.59 \pm 0.95,3.82 \pm 1.20$, and $3.90 \pm 1.45 \mathrm{mmol} / \mathrm{L}$ respectively after PSM adjustments.

Around 1.3\%, 0\% and 1.3\% AMI patients reached target LDL level among Statin, Statin plus Ezetimibe, triple therapy group during admission. In the $1^{\text {st }}$ month follow-up, the achieved rate was $10.7 \%, 28.6 \%$, $55.3 \%$ and $0.0 \%, 17.9 \%, 43.8 \%$ after 3month respectively(Fig4.A).Also, the mean LDL level was significantly decreased in triple therapy patients compared to the other two groups, with $1.43 \pm 1.06,1.96 \pm 0.49,2.04 \pm 0.81 \mathrm{mmol} / \mathrm{L} \quad$ in the $1^{\text {st }}$ month and $1.40 \pm 0.50,2.06 \pm 0.42,2.37 \pm 1.13$ $\mathrm{mmol} / \mathrm{L}$ after 3-month follow-up(Table3 and Fig4.B). Additionally, a similar decrease was observed in ApoB level, triple medication users reached $0.59 \pm 0.290 .61 \pm 0.20 \mathrm{~g} / \mathrm{L}$ in $1^{\text {st }}$ month and $3^{\text {rd }}$ month, compared to $0.75 \pm 0.17,0.80 \pm 0.13 \mathrm{~g} / \mathrm{L}$ in Statin group and $0.76 \pm 0.20,0.83 \pm 0.29 \mathrm{~g} / \mathrm{L}$ in Statin plus Ezetimibe group. 5.3\% AMI patients re-hospitalized with triple therapy, which was $6.7 \%$ and $6.0 \%$ lower than those in Statin and Statin plus Ezetimibe users. 


\section{Discussion}

In this single-centre, retrospective, population-based study, we have found that in-hospital initiation of PCSK9 has been effective in short-term lipid control among AMI patients. In both PCSK9i plus statin therapy with or without ezetimibe cohort, the mean LDL levels decrease by more than $60 \%$. In addition, more than $50 \%$ of patients of the above two groups reach the target LDL-C level after one-month treatment. PCSK9i plus statin therapy with or without ezetimibe exhibit a better lipid-lowering effect as compared to statin or statin plus ezetimibe therapy.

Previously, PCSK9 inhibitors have been shown to reduce major cardiovascular events in secondary prevention among patients with and without clinically significant atherosclerotic cardiovascular disease (ASCVD). EVOPACS study is the first study to evaluate the very early application of PCSK9i in ACS patients ${ }^{18}$. It is confirmed that compared with a high-intensity statin alone, the addition of evolocumab brings a very significant reduction in LDL-C levels. Also, the ODYSSEY study demonstrated that alirocumab added to intensive statin therapy reduced the occurrence of both Type 1 and Type $2 \mathrm{MI}$ among patients after a recent $\mathrm{ACS}^{19}$. Our study is the first to the best of our knowledge to investigate the lipid profile alteration as well as the short-term outcomes of PCSK9i initiated together with statin among AMI patients focusing on the real-world evidence. Similar to EVOPACS study ${ }^{18}$, our results show that LDL is significantly decreased via PCSK9i treatment after 1-month and 3-month follow-up when added to either statin or statin plus ezetimibe therapy. It is also noteworthy that $A p o B$, the primary apolipoprotein of LDL particles, exhibited the same trend as LDL among each treatment group, further proving the efficiency of PCSK9i in lipid-lowering strategy.

Besides, our study shows decreased readmission rate in the short-term follow-up via PCSK9i therapy. Mechanistically, previous studies have proved that after adjusting for ACSVD risk factors (including LDL level), serum PCSK9 levels were linearly associated with the fraction and amount of necrotic core tissue in coronary atherosclerosis ${ }^{20}$. And compared with healthy volunteers, a significantly higher concentration of PCSK9 was observed in patients with ACS ${ }^{21}$. Additionally, increased PCSK9 levels were associated with higher platelet reactivity and might be a possible predictor of ischemic events in ACS patients undergoing $\mathrm{PCl}^{22}$. Taken together, our results have provided further clinical benefits that PCSK9i might exert lasting cardiovascular benefits on AMI patients apart from the lipid control. The reduction of the readmission rate is only based on a 3-month follow-up. Long-term follow-up data are warranted to further validate the efficacy of the in-hospital initiation of PCSK9; ${ }^{23}$.

Notably, in terms of lipid-lowering effect, we have found that triple therapy of PCSK9i, statin and ezetimibe is not superior to statin plus evolocumab treatment before PSM adjustment. Several potential mechanisms may account for this phenomenon: First, most patients with triple treatment have extremely high LDL levels on admission, which was even $20 \%$ higher than that of the dual therapy group. Second, different lipid-lowering mechanisms also influence the effect. Ezetimibe inhibits the absorption of cholesterol from the small intestine and decreases the amount of cholesterol normally available to liver cells; the lower levels of cholesterol in the liver cells lead them to absorb more cholesterol from circulation 
and thus "indirectly" lowering the levels of circulating cholesterol. On the other hand, evolocumab inhibits PCSK9 from binding to LDL receptors on the liver surface, and there are more LDL receptors on the surface of liver cells to remove LDL-C from the blood directly. At last, only 75 triple therapy users were included in this study and probably the reduced compliance may also affect the result.

There are several limitations in the current work. First, this study is limited in its single-centre, retrospective and observational nature. Future multicenter studies based on longer follow-up are required. Also, although the dosage and frequency of statin (20 mg atorvastatin or $10 \mathrm{mg}$ rosuvastatin per day) are fixed, the data on whether statin therapy was started during or before hospital admission, and whether statin was not allowed due to its side effects are inaccessible so that it is not possible to match this situation in the four groups. However, the initiation, dosage and frequency of Evolocumab were fixed among all the groups in this study.

\section{Conclusions}

In conclusion, through this retrospective, PSM-adjusted, real-world cohort study, we have found that PCSK9i has been effective in short-term lipid and readmission control among AMI patients. The long term effectiveness, as well as the specific mechanism of PCSK9i for reducing major cardiovascular events, remain to be explored.

\section{Declarations}

\section{Ethics approval and consent to participate}

Written informed consent was obtained from all study participants, with ethnic committee approval at the First Affiliated Hospital of Xi'an Jiaotong University.

\section{Consent for publication}

All authors have reviewed the final version of the manuscript and approved it for publication.

\section{Availability of data and materials}

The datasets used or analysed during the current study are available from the corresponding author on reasonable request.

\section{Competing Interests}

Not applicable. 


\section{Funding}

This study was supported by National Natural Science Foundation of China (No.81800390,82170464,81822005,81970351,81941005,82100477,92049203), National Key R\&D Program of China (2019YFA0802300, 2018YFC1311505), Key Research and Development Program of Shaanxi (No. 2020KW-049, 2021 KWZ-25, S2020-YF-GHMS-0014, 2017SF-085, 2020GXLH-Y-015), Central University Basic Science Foundation of China (119132971000056); and the Clinical Research Award of the First Affiliated Hospital of Xi'an Jiaotong University, China (No. XJTU1AF-CRF-2018-025区XJTU1AFCRF-2017-006)

\section{Authors' contributions}

JS, BL and ZY participated in the design of the study. JL, BL and HL collected the patients' data and did the follow-up. HL, YL and GTJ performed the statistical analysis. YL, HW, YW and CW finished the patients' follow-up. JS, JL and BL drafted the manuscript. All authors approved the final manuscript.

\section{Acknowledgements}

The authors wish to acknowledge the assistance of Biobank from the First Affiliated Hospital of Xi'an Jiaotong University with the data extraction and preparation of the manuscript.

\section{References}

1. Roth GA, Mensah GA, Johnson CO, Addolorato G, Ammirati E, Baddour LM, Barengo NC, Beaton AZ, Benjamin EJ, Benziger CP, Bonny A, Brauer M, Brodmann M, Cahill TJ, Carapetis J, Catapano AL, Chugh SS, Cooper LT, Coresh J, Criqui M, DeCleene N, Eagle KA, Emmons-Bell S, Feigin VL, Fernandez-Sola J, Fowkes G, Gakidou E, Grundy SM, He FJ, Howard G, Hu F, Inker L, Karthikeyan G, Kassebaum N, Koroshetz W, Lavie C, Lloyd-Jones D, Lu HS, Mirijello A, Temesgen AM, Mokdad A, Moran AE, Muntner P, Narula J, Neal B, Ntsekhe M, Moraes de Oliveira G, Otto C, Owolabi M, Pratt M, Rajagopalan S, Reitsma M, Ribeiro ALP, Rigotti N, Rodgers A, Sable C, Shakil S, Sliwa-Hahnle K, Stark B, Sundstrom J, Timpel P, Tleyjeh IM, Valgimigli M, Vos T, Whelton PK, Yacoub M, Zuhlke L, Murray C, Fuster V and Group G-N-JGBoCDW. Global Burden of Cardiovascular Diseases and Risk Factors, 1990-2019: Update From the GBD 2019 Study. J Am Coll Cardiol. 2020;76:2982-3021.

2. DeFilippis AP, Chapman AR, Mills NL, de Lemos JA, Arbab-Zadeh A, Newby LK and Morrow DA. Assessment and Treatment of Patients With Type 2 Myocardial Infarction and Acute Nonischemic Myocardial Injury. Circulation. 2019;140:1661-1678.

3. Dhruva SS, Ross JS, Mortazavi BJ, Hurley NC, Krumholz HM, Curtis JP, Berkowitz A, Masoudi FA, Messenger JC, Parzynski CS, Ngufor C, Girotra S, Amin AP, Shah ND and Desai NR. Association of Use of an Intravascular Microaxial Left Ventricular Assist Device vs Intra-aortic Balloon Pump With 
In-Hospital Mortality and Major Bleeding Among Patients With Acute Myocardial Infarction Complicated by Cardiogenic Shock. JAMA. 2020;323:734-745.

4. Lou B, Luo Y, Hao X, Sun L, Deng Y, Guo M, Liu J, Zhou B, Yuan Z and She J. Clinical characteristics and protective factors in patients with acute myocardial infarction undergoing in-hospital myocardial free wall rupture: a single-center, retrospective analysis. J Investig Med. 2019;67:1097-1102.

5. Schrage B, Ibrahim K, Loehn T, Werner N, Sinning JM, Pappalardo F, Pieri M, Skurk C, Lauten A, Landmesser U, Westenfeld R, Horn P, Pauschinger M, Eckner D, Twerenbold R, Nordbeck P, Salinger T, Abel P, Empen K, Busch MC, Felix SB, Sieweke JT, Moller JE, Pareek N, Hill J, MacCarthy P, Bergmann MW, Henriques JPS, Mobius-Winkler S, Schulze PC, Ouarrak T, Zeymer U, Schneider S, Blankenberg S, Thiele H, Schafer A and Westermann D. Impella Support for Acute Myocardial Infarction Complicated by Cardiogenic Shock. Circulation. 2019;139:1249-1258.

6. Gencer B, Mach F, Murphy SA, De Ferrari GM, Huber K, Lewis BS, Ferreira J, Kurtz CE, Wang H, Honarpour N, Keech AC, Sever PS, Pedersen TR, Sabatine MS and Giugliano RP. Efficacy of Evolocumab on Cardiovascular Outcomes in Patients With Recent Myocardial Infarction: A Prespecified Secondary Analysis From the FOURIER Trial. JAMA Cardiol. 2020;5:952-957.

7. Seidah NG, Awan Z, Chretien M and Mbikay M. PCSK9: a key modulator of cardiovascular health. Circ Res. 2014;114:1022-36.

8. Yan BP, Chiang FT, Ambegaonkar B, Brudi P, Horack M, Lautsch D, Vyas A and Gitt AK. Low-density lipoprotein cholesterol target achievement in patients surviving an acute coronary syndrome in Hong Kong and Taiwan - findings from the Dyslipidemia International Study II. Int J Cardiol. 2018;265:1-5.

9. Mach F, Baigent C, Catapano AL, Koskinas KC, Casula M, Badimon L, Chapman MJ, De Backer GG, Delgado V, Ference BA, Graham IM, Halliday A, Landmesser U, Mihaylova B, Pedersen TR, Riccardi G, Richter DJ, Sabatine MS, Taskinen MR, Tokgozoglu L, Wiklund O and Group ESCSD. 2019 ESC/EAS Guidelines for the management of dyslipidaemias: lipid modification to reduce cardiovascular risk. Eur Heart J. 2020;41:111-188.

10. Cannon CP, de Lemos JA, Rosenson RS, Ballantyne CM, Liu Y, Gao Q, Palagashvilli T, Alam S, Mues KE, Bhatt DL, Kosiborod MN and Investigators G. Use of Lipid-Lowering Therapies Over 2 Years in GOULD, a Registry of Patients With Atherosclerotic Cardiovascular Disease in the US. JAMA Cardiol. 2021.

11. Santos RD, Ruzza A, Hovingh GK, Wiegman A, Mach F, Kurtz CE, Hamer A, Bridges I, Bartuli A, Bergeron J, Szamosi T, Santra S, Stefanutti C, Descamps OS, Greber-Platzer S, Luirink I, Kastelein JJP, Gaudet D and Investigators H-R. Evolocumab in Pediatric Heterozygous Familial Hypercholesterolemia. N Engl J Med. 2020;383:1317-1327.

12. Burnett JR and Hooper AJ. PCSK9 - A Journey to Cardiovascular Outcomes. N Engl J Med. 2018;379:2161-2162.

13. Schwartz GG, Steg PG, Szarek M, Bhatt DL, Bittner VA, Diaz R, Edelberg JM, Goodman SG, Hanotin C, Harrington RA, Jukema JW, Lecorps G, Mahaffey KW, Moryusef A, Pordy R, Quintero K, Roe MT, 
Sasiela WJ, Tamby JF, Tricoci P, White HD, Zeiher AM, Committees 00 and Investigators. Alirocumab and Cardiovascular Outcomes after Acute Coronary Syndrome. N Engl J Med. 2018;379:2097-2107.

14. Raygor V and Khera A. New Recommendations and Revised Concepts in Recent Guidelines on the Management of Dyslipidemias to Prevent Cardiovascular Disease: the 2018 ACC/AHA and 2019 ESC/EAS Guidelines. Curr Cardiol Rep. 2020;22:87.

15. Dykun I, Mahabadi AA and Rassaf T. A clinical perspective on the 2019 ESC/EAS guidelines for the management of dyslipidaemias: PCSK-9 inhibitors for all? Eur Heart J. 2020;41:2331.

16. Atherosclerosis, Coronary Heart Disease Working Group of Chinese Society of C and Editorial Board of Chinese Journal of $\mathrm{C}$. [Chinese expert consensus on lipid management of very high-risk atherosclerotic cardiovascular disease patients]. Zhonghua Xin Xue Guan Bing Za Zhi. 2020;48:280286.

17. Ibanez B, James S, Agewall S, Antunes MJ, Bucciarelli-Ducci C, Bueno H, Caforio ALP, Crea F, Goudevenos JA, Halvorsen S, Hindricks G, Kastrati A, Lenzen MJ, Prescott E, Roffi M, Valgimigli M, Varenhorst C, Vranckx P, Widimsky P and Group ESCSD. 2017 ESC Guidelines for the management of acute myocardial infarction in patients presenting with ST-segment elevation: The Task Force for the management of acute myocardial infarction in patients presenting with ST-segment elevation of the European Society of Cardiology (ESC). Eur Heart J. 2018;39:119-177.

18. Koskinas KC, Windecker S, Pedrazzini G, Mueller C, Cook S, Matter CM, Muller O, Haner J, Gencer B, Crljenica C, Amini P, Deckarm O, Iglesias JF, Raber L, Heg D and Mach F. Evolocumab for Early Reduction of LDL Cholesterol Levels in Patients With Acute Coronary Syndromes (EVOPACS). J Am Coll Cardiol. 2019;74:2452-2462.

19. White HD, Steg PG, Szarek M, Bhatt DL, Bittner VA, Diaz R, Edelberg JM, Erglis A, Goodman SG, Hanotin C, Harrington RA, Jukema JW, Lopes RD, Mahaffey KW, Moryusef A, Pordy R, Roe MT, Sritara P, Tricoci P, Zeiher AM, Schwartz GG and Investigators OO. Effects of alirocumab on types of myocardial infarction: insights from the ODYSSEY OUTCOMES trial. Eur Heart J. 2019;40:2801-2809.

20. Cheng JM, Oemrawsingh RM, Garcia-Garcia HM, Boersma E, van Geuns RJ, Serruys PW, Kardys I and Akkerhuis KM. PCSK9 in relation to coronary plaque inflammation: Results of the ATHEROREMOIVUS study. Atherosclerosis. 2016;248:117-22.

21. Burchardt P, Rzezniczak J, Dudziak J, Dzumak A, Marchlewski T, Ganowicz-Kaatz T, Popiak M, Slomczynski M, Jezierski M, Laskowski W, Luczak T and Plewa R. Evaluation of plasma PCSK9 concentrations, transcript of LDL receptor, as well as the total number of monocyte LDL receptors in acute coronary syndrome patients. Cardiol J. 2016;23:604-609.

22. Navarese EP, Kolodziejczak M, Winter MP, Alimohammadi A, Lang IM, Buffon A, Lip GY and SillerMatula JM. Association of PCSK9 with platelet reactivity in patients with acute coronary syndrome treated with prasugrel or ticagrelor: The PCSK9-REACT study. Int J Cardiol. 2017;227:644-649.

23. Ibrahim NE, Pina IL, Camacho A, Bapat D, Felker GM, Maisel AS, Butler J, Prescott MF, Abbas CA, Solomon SD, Januzzi JL, Jr., Prospective Study of Biomarkers SI and Ventricular Remodeling During Entresto Therapy for Heart Failure Study I. Sex-based differences in biomarkers, health status, and 
reverse cardiac remodelling in patients with heart failure with reduced ejection fraction treated with sacubitril/valsartan. Eur J Heart Fail. 2020;22:2018-2025.

\section{Tables}

\section{Table 1}

Distribution of Demographic and Clinical Characteristics According to different lipid-lowering strategies in AMl patients. 
Statin

Statin+

Statin+

Statin+

Ezetimibe

Evolocumab

Ezetimibe+

Evolocumab

\begin{tabular}{|c|c|c|c|c|c|}
\hline \multicolumn{2}{|l|}{ Age(years) } & $62.90 \pm 11.91$ & $58.73 \pm 12.16$ & $57.72 \pm 11.07$ & $54.38 \pm 11.77$ \\
\hline \multicolumn{2}{|c|}{ Female Sex(\%) } & 20.3 & 21.0 & 15.7 & 18.8 \\
\hline \multicolumn{2}{|c|}{ SBP(mmHg) } & $123.41 \pm 22.24$ & $125.20 \pm 22.79$ & $127.54 \pm 22.20$ & $122.72 \pm 23.04$ \\
\hline \multicolumn{2}{|c|}{ DBP(mmHg) } & $77.17 \pm 14.53$ & $79.01 \pm 15.02$ & $82.36 \pm 14.49$ & $78.98 \pm 15.32$ \\
\hline \multicolumn{2}{|l|}{$\mathrm{EF}(\%)$} & $51.11 \pm 10.27$ & $52.81 \pm 10.39$ & $51.11 \pm 10.27$ & $51.27 \pm 9.72$ \\
\hline \multicolumn{2}{|c|}{ Pro-BNP(pg/mL) } & 2071.69 & 1334.93 & 2071.69 & 1135.26 \\
\hline \multicolumn{2}{|l|}{ HbA1c(\%) } & $6.33 \pm 1.45$ & $6.29 \pm 1.44$ & $6.33 \pm 1.45$ & $6.75 \pm 2.00$ \\
\hline \multicolumn{2}{|c|}{ Cre(umol/L) } & 77.94 & 70.48 & 69.36 & 62.97 \\
\hline \multicolumn{2}{|c|}{ UA(umol/L) } & 333.91 & 340.59 & 330.43 & 330.08 \\
\hline \multicolumn{2}{|c|}{$\mathrm{TG}(\mathrm{mmol} / \mathrm{L})$} & $1.48 \pm 0.99$ & $1.94 \pm 0.66$ & $1.57 \pm 0.74$ & $1.92 \pm 1.02$ \\
\hline \multicolumn{2}{|c|}{ HDL(mmol/L) } & $0.93 \pm 0.22$ & $0.98 \pm 0.24$ & $1.00 \pm 0.21$ & $1.00 \pm 0.23$ \\
\hline \multicolumn{2}{|c|}{ TCDL(mmol/L) } & $3.93 \pm 0.99$ & $4.76 \pm 1.25$ & $4.96 \pm 1.19$ & $5.69 \pm 1.50$ \\
\hline \multicolumn{2}{|l|}{ ApoA(g/L) } & $1.05 \pm 0.19$ & $1.09 \pm 0.19$ & $1.09 \pm 0.17$ & $1.09 \pm 0.20$ \\
\hline \multicolumn{2}{|l|}{$\mathrm{ApoB}(\mathrm{g} / \mathrm{L})$} & $0.77 \pm 0.20$ & $0.95 \pm 0.24$ & $1.00 \pm 0.23$ & $1.16 \pm 0.29$ \\
\hline \multicolumn{2}{|c|}{ ApoE(mg/L) } & $35.64 \pm 14.04$ & $41.59 \pm 18.67$ & $41.96 \pm 12.92$ & $46.68 \pm 19.88$ \\
\hline \multicolumn{2}{|c|}{ Lp(a) (mg/L) } & 261.68 & 302.22 & 330.56 & 368.69 \\
\hline \multicolumn{2}{|l|}{ Death (\%) } & 1.9 & 0.7 & 0.8 & 0.0 \\
\hline \multicolumn{2}{|c|}{ Readmission (\%) } & 10.4 & 14.7 & 4.0 & 5.3 \\
\hline \multirow{6}{*}{$\begin{array}{l}\text { LDL } \\
\text { (mmol/L) }\end{array}$} & Admission & $2.25 \pm 0.74$ & $2.95 \pm 1.03$ & $3.24 \pm 0.98$ & $3.90 \pm 1.45$ \\
\hline & Under Target & 11.8 & 4.0 & 3.2 & 1.3 \\
\hline & Follow-up(1m) & $1.60 \pm 0.51$ & $1.87 \pm 0.75$ & $0.93 \pm 0.63$ & $1.41 \pm 1.02$ \\
\hline & Under Target & 37.0 & 28.8 & 79.5 & 55.3 \\
\hline & Follow-up(3m) & $1.60 \pm 0.54$ & $1.90 \pm 0.82$ & $1.13 \pm 0.67$ & $1.40 \pm 0.50$ \\
\hline & Under Target & 40.6 & 29.3 & 80.0 & 43.8 \\
\hline
\end{tabular}

Data were shown in mean $\pm S D$, median or $n(\%)$. 
SBP, systolic blood pressure; DBP, diastolic blood pressure; EF, eject fraction; HbA1c, haemoglobin A1 c; Cre, creatinine; UA, uric acid; TG, triglyceride; LDL, low density lipoprotein; HDL, high density lipoprotein; ApoA, apolipoprotein A; ApoB, apolipoprotein B; ApoE, apolipoprotein E; TCDL, total cholesterol lipoprotein. Lp(a), Lipoprotein(a)

\section{Table 2}

Short-term lipid profile alteration among Statin plus Evolocumab / Statin/ Statin plus Ezetimibe lipidlowering strategies in AMI patients after PSM adjustment. 


\section{Statin}

Statin+

Statin+

p1

p2

Ezetimibe Evolocumab

\begin{tabular}{|c|c|c|c|c|c|c|}
\hline \multirow{3}{*}{$\begin{array}{l}\text { LDL } \\
\text { (mmol/L) }\end{array}$} & Admission & $3.11 \pm 1.02$ & $3.24 \pm 1.13$ & $3.24 \pm 0.98$ & 0.303 & 0.968 \\
\hline & Follow-up(1m) & $1.58 \pm 0.44$ & $1.96 \pm 0.82$ & $0.92 \pm 0.62$ & $<0.001$ & $<0.001$ \\
\hline & Follow-up(3m) & $1.61 \pm 0.49$ & $2.10 \pm 0.82$ & $1.17 \pm 0.73$ & 0.048 & $<0.001$ \\
\hline \multirow{3}{*}{$\begin{array}{l}\text { TG } \\
(\mathrm{mmol} / \mathrm{L})\end{array}$} & Admission & $1.56 \pm 1.01$ & $1.55 \pm 0.72$ & $1.57 \pm 0.74$ & 0.927 & 0.823 \\
\hline & Follow-up(1m) & $1.33 \pm 0.67$ & $1.53 \pm 0.70$ & $1.29 \pm 0.65$ & 0.121 & 0.038 \\
\hline & Follow-up(3m) & $1.57 \pm 1.13$ & $1.66 \pm 0.84$ & $1.18 \pm 0.51$ & 0.214 & 0.011 \\
\hline \multirow{3}{*}{$\begin{array}{l}\text { HDL } \\
\text { (mmol/L) }\end{array}$} & Admission & $0.98 \pm 0.22$ & $1.02 \pm 0.22$ & $0.99 \pm 0.21$ & 0.593 & 0.364 \\
\hline & Follow-up(1m) & $1.01 \pm 0.22$ & $1.05 \pm 0.25$ & $1.03 \pm 0.24$ & 0.042 & 0.654 \\
\hline & Follow-up(3m) & $1.00 \pm 0.18$ & $1.00 \pm 0.25$ & $1.14 \pm 0.32$ & 0.145 & 0.078 \\
\hline \multirow{3}{*}{$\begin{array}{l}\text { ApoA } \\
(g / L)\end{array}$} & Admission & $1.08 \pm 0.20$ & $1.11 \pm 0.20$ & $1.09 \pm 0.17$ & 0.785 & 0.240 \\
\hline & Follow-up(1m) & $1.17 \pm 0.18$ & $1.18 \pm 0.18$ & $1.21 \pm 0.19$ & 0.223 & 0.390 \\
\hline & Follow-up(3m) & $1.20 \pm 0.17$ & $1.15 \pm 0.20$ & $1.25 \pm 0.24$ & 0.525 & 0.122 \\
\hline \multirow{3}{*}{$\begin{array}{l}\text { ApoB } \\
(g / L)\end{array}$} & Admission & $0.99 \pm 0.21$ & $1.00 \pm 0.26$ & $1.00 \pm 0.23$ & 0.676 & 0.974 \\
\hline & Follow-up(1m) & $0.64 \pm 0.16$ & $0.70 \pm 0.22$ & $0.39 \pm 0.20$ & $<0.001$ & $<0.001$ \\
\hline & Follow-up(3m) & $0.59 \pm 0.15$ & $0.75 \pm 0.22$ & $0.46 \pm 0.20$ & 0.038 & $<0.001$ \\
\hline \multirow{3}{*}{$\begin{array}{l}\text { ApoE } \\
\text { (mg/L) }\end{array}$} & Admission & $41.83 \pm 18.16$ & $41.60 \pm 16.61$ & $41.96 \pm 12.92$ & 0.950 & 0.853 \\
\hline & Follow-up(1m) & $33.82 \pm 11.29$ & $34.46 \pm 11.93$ & $20.79 \pm 9.39$ & $<0.001$ & $<0.001$ \\
\hline & Follow-up(3m) & $32.83 \pm 10.80$ & $30.44 \pm 9.50$ & $21.59 \pm 8.18$ & 0.018 & 0.013 \\
\hline \multirow[t]{3}{*}{$\mathrm{LP}(\mathrm{a})(\mathrm{mg} / \mathrm{L})$} & Admission & 331.77 & 310.66 & 330.55 & 0.975 & 0.679 \\
\hline & Follow-up(1m) & 281.96 & 283.66 & 271.18 & 0.902 & 0.876 \\
\hline & Follow-up(3m) & 358.29 & 370.88 & 345.92 & 0.951 & 0.867 \\
\hline \multirow{3}{*}{$\begin{array}{l}\text { TCDL } \\
\text { (mmol/L) }\end{array}$} & Admission & $4.97 \pm 1.19$ & $5.03 \pm 1.30$ & $5.00 \pm 1.16$ & 0.799 & 0.884 \\
\hline & Follow-up(1m) & $3.16 \pm 0.58$ & $3.57 \pm 0.90$ & $2.37 \pm 0.74$ & $<0.001$ & $<0.001$ \\
\hline & Follow-up(3m) & $3.18 \pm 0.56$ & $3.72 \pm 1.02$ & $2.79 \pm 0.72$ & 0.074 & $<0.001$ \\
\hline
\end{tabular}

Data were shown in mean $\pm S D$, median or $\mathrm{n}(\%) . p 1$, Statin plus Evolocumab vs. Statin; $p 2$, Statin plus Evolocumab vs. Statin plus Ezetimibe.

$T G$, triglyceride; LDL, low density lipoprotein; HDL, high density lipoprotein; ApoA, apolipoprotein A; ApoB, apolipoprotein B; ApoE, apolipoprotein E; TCDL, total cholesterol lipoprotein. Lp(a), Lipoprotein(a) 


\section{Table 3}

Short-term lipid profile alteration among Statin plus Ezetimibe plus Evolocumab / Statin/ Statin plus Ezetimibe lipid-lowering strategies in AMI patients after PSM adjustment. 
Statin

Statin

+Ezetimibe

\begin{tabular}{|c|c|c|c|c|c|c|}
\hline \multirow{3}{*}{$\begin{array}{l}\text { LDL } \\
\text { (mmol/L) }\end{array}$} & Admission & $3.59 \pm 0.95$ & $3.82 \pm 1.20$ & $3.90 \pm 1.45$ & 0.060 & 0.666 \\
\hline & $\begin{array}{l}\text { Follow- } \\
\text { up }(1 \mathrm{~m})\end{array}$ & $1.96 \pm 0.49$ & $2.04 \pm 0.81$ & $1.43 \pm 1.06$ & 0.001 & 0.001 \\
\hline & $\begin{array}{l}\text { Follow- } \\
\text { up }(3 m)\end{array}$ & $2.06 \pm 0.42$ & $2.37 \pm 1.13$ & $1.40 \pm 0.50$ & $<0.001$ & $<0.001$ \\
\hline \multirow{3}{*}{$\begin{array}{l}\text { TG } \\
(\mathrm{mmol} / \mathrm{L})\end{array}$} & Admission & $2.08 \pm 1.12$ & $1.92 \pm 1.04$ & $1.93 \pm 1.01$ & 0.311 & 0.948 \\
\hline & $\begin{array}{l}\text { Follow- } \\
\text { up }(1 \mathrm{~m})\end{array}$ & $1.72 \pm 0.71$ & $1.58 \pm 0.68$ & $1.50 \pm 0.72$ & 0.148 & 0.539 \\
\hline & $\begin{array}{l}\text { Follow- } \\
\text { up(3m) }\end{array}$ & $1.53 \pm 0.64$ & $1.82 \pm 0.74$ & $1.74 \pm 1.17$ & 0.534 & 0.796 \\
\hline \multirow{3}{*}{$\begin{array}{l}\mathrm{HDL} \\
(\mathrm{mmol} / \mathrm{L})\end{array}$} & Admission & $0.98 \pm 0.24$ & $1.01 \pm 0.22$ & $1.00 \pm 0.23$ & 0.472 & 0.818 \\
\hline & $\begin{array}{l}\text { Follow- } \\
\text { up }(1 \mathrm{~m})\end{array}$ & $0.99 \pm 0.24$ & $0.99 \pm 0.21$ & $0.94 \pm 0.21$ & 0.253 & 0.176 \\
\hline & $\begin{array}{l}\text { Follow- } \\
\text { up }(3 \mathrm{~m})\end{array}$ & $1.03 \pm 0.29$ & $1.00 \pm 0.27$ & $0.95 \pm 0.18$ & 0.316 & 0.491 \\
\hline
\end{tabular}

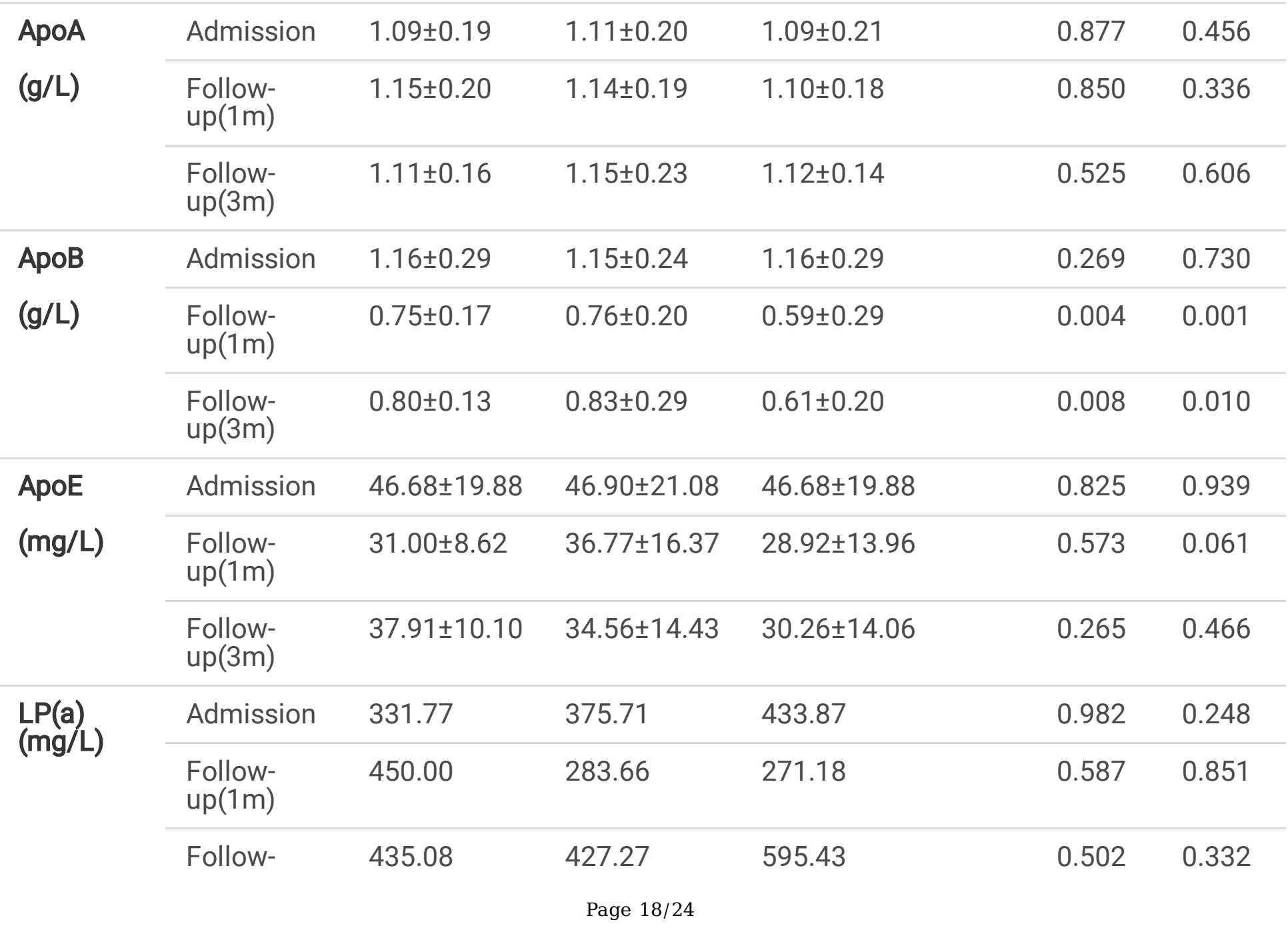


up(3m)

\begin{tabular}{lllllll} 
TCDL & Admission & $5.55 \pm 1.14$ & $5.72 \pm 1.30$ & $5.79 \pm 1.42$ & 0.181 & 0.739 \\
\cline { 2 - 7 }$(\mathrm{mmol} / \mathrm{L})$ & $\begin{array}{l}\text { Follow- } \\
\text { up(1m) }\end{array}$ & $3.52 \pm 0.65$ & $3.55 \pm 0.89$ & $2.82 \pm 1.18$ & $<0.001$ & $<0.001$ \\
\cline { 2 - 7 } & $\begin{array}{l}\text { Follow- } \\
\text { up(3m) }\end{array}$ & $3.65 \pm 0.74$ & $3.93 \pm 1.39$ & $2.97 \pm 0.64$ & 0.009 & 0.003
\end{tabular}

Data were shown in mean $\pm S D$, median or $\mathrm{n}(\%) . p 1$, Statin plus Ezetimibe plus Evolocumab vs. Statin; $p 2$, Statin plus Ezetimibe plus Evolocumab vs. Statin plus Ezetimibe.

TG, triglyceride; LDL, low density lipoprotein; HDL, high density lipoprotein; ApoA, apolipoprotein A; ApoB, apolipoprotein B; ApoE, apolipoprotein E; TCDL, total cholesterol lipoprotein. $\operatorname{Lp}(a)$, Lipoprotein(a).

\section{Figures}




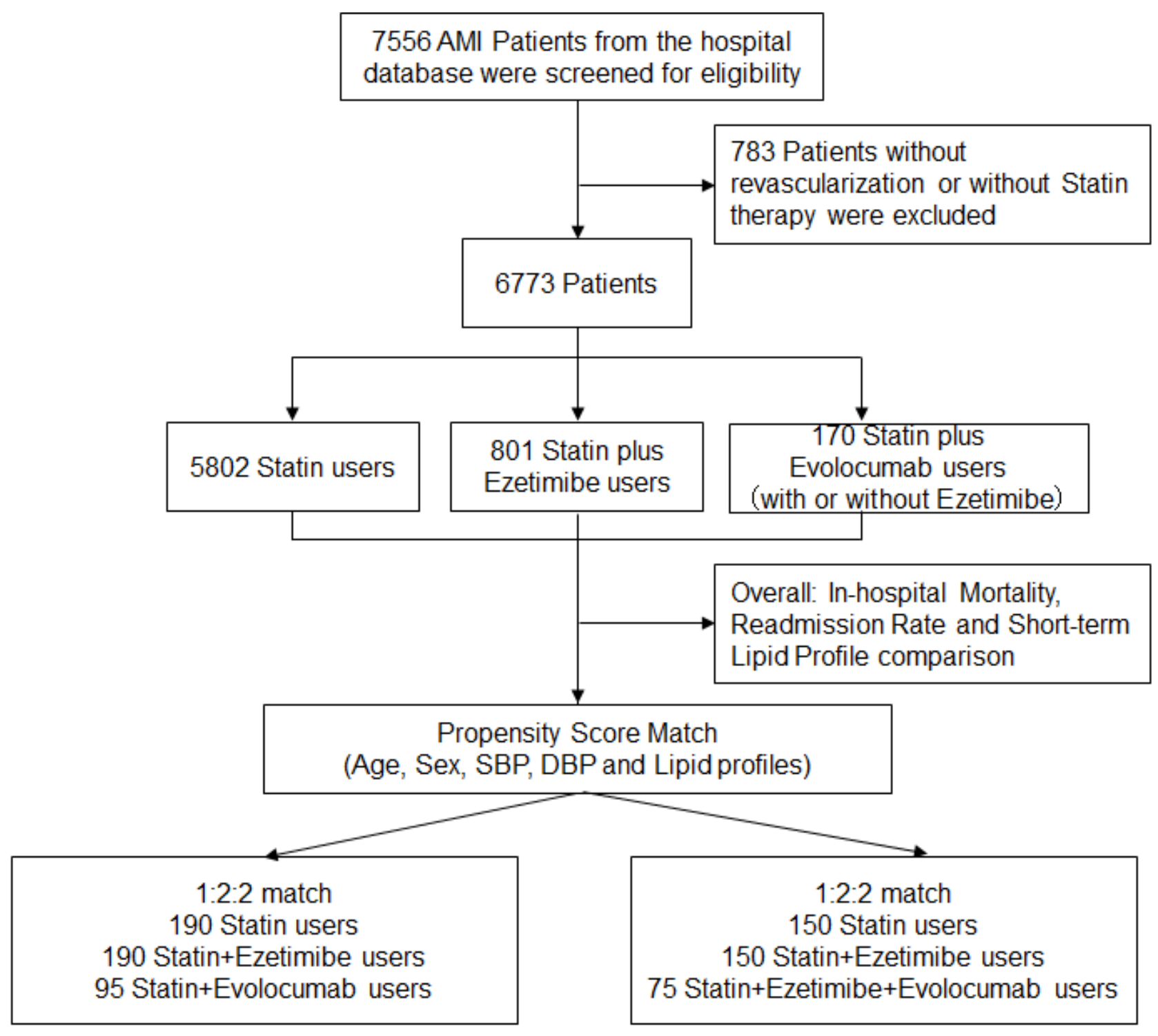

Primary Endpoint:

Short-term Lipid Profile Alteration.

( $1^{\text {st }}$ and $3^{\text {rd }}$ month follow-up)

Secondary Outcome:

Readmission.

Figure 1. Patients Selection, Propensity Score Matching and Follow-up.

\section{Figure 1}

Please See image above for figure legend. 
A.

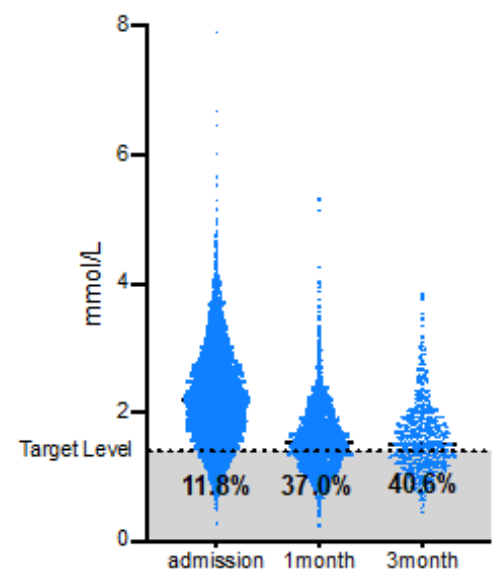

Statin+Ezetimibe

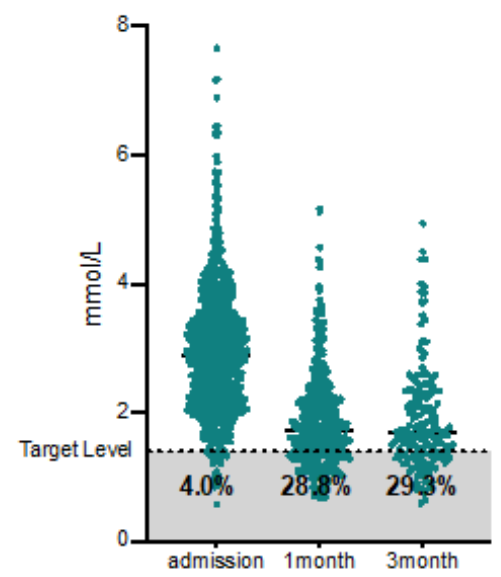

Statin+Evolocumab

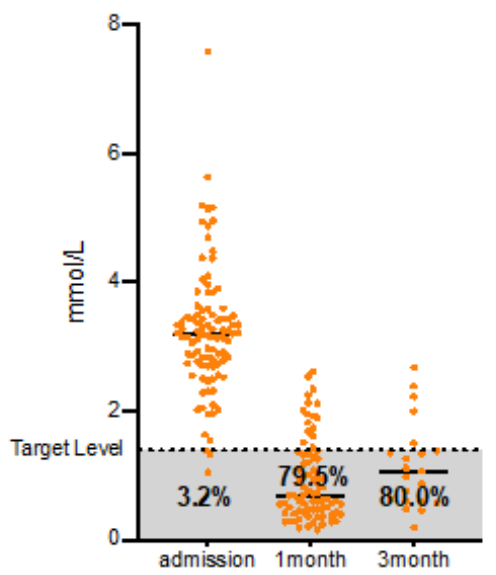

Statin+Ezetimibe+Evolocumab

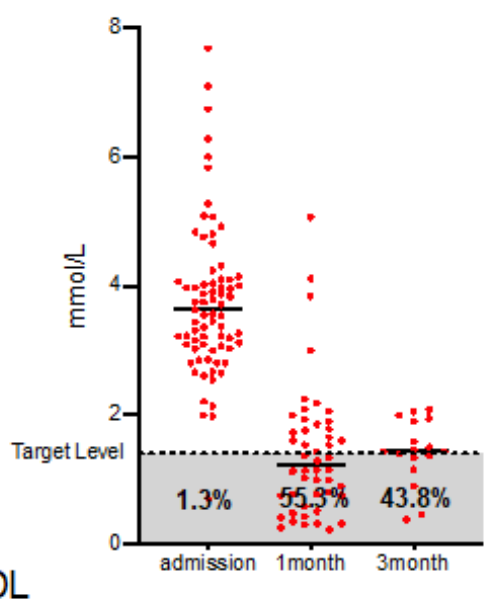

LDL

- Statin+Ezetimibe

- Statin+Evolocumab

$\rightarrow-$ Statin+Ezetimibe +Evolocumab

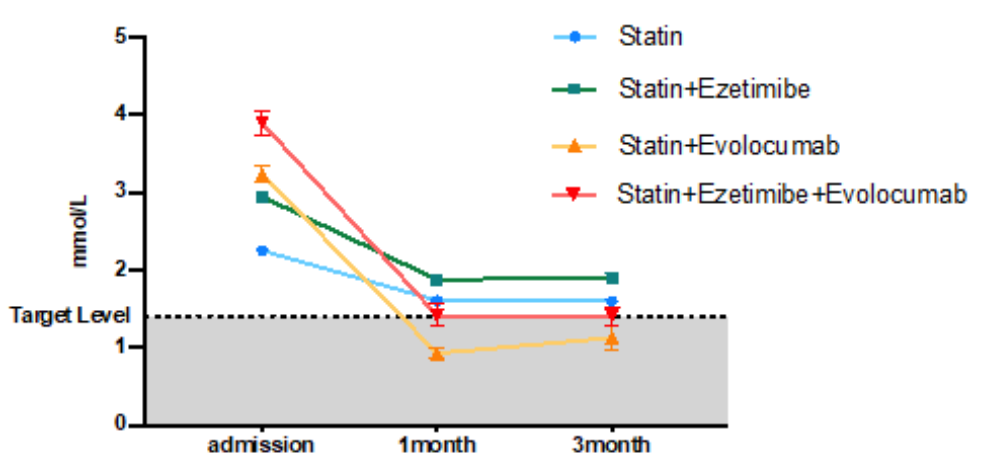

B.

Figure.2 LDL level and compliance rate on admission and short-term follow-up among different lipidlowering strategies in AMI patients.

(A). LDL level and compliance rate among different lipid-lowering strategies on admission and $1^{\text {st }}$ and $3^{\text {rd }}$ month follow-up. Each point represent one AMI patient's lipid data. (B). LDL alternation among different lipid-lowering strategies on admission and $1^{\text {st }}$ and $3^{\text {rd }}$ month follow-up. Data were shown in mean \pm SEM LDL Target Level $=1.4 \mathrm{mmol} / \mathrm{L}$.

\section{Figure 2}

Please See image above for figure legend. 
A.

Statin

Statin+Ezetimibe

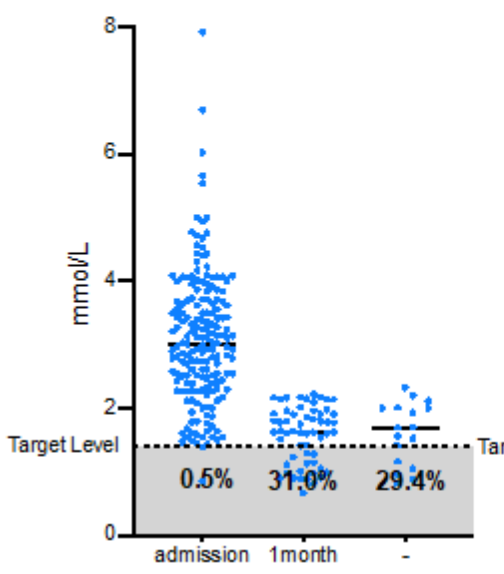

B.

D.

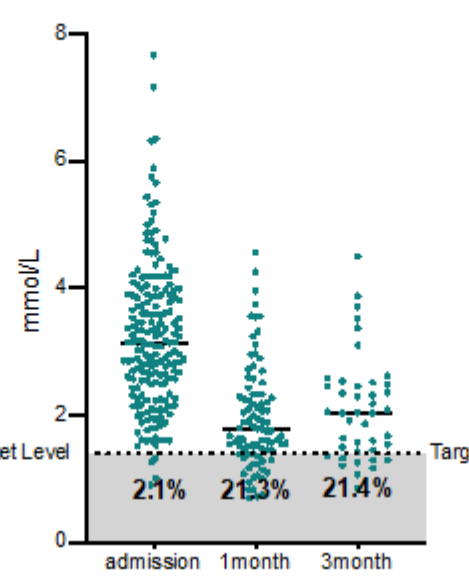

c.
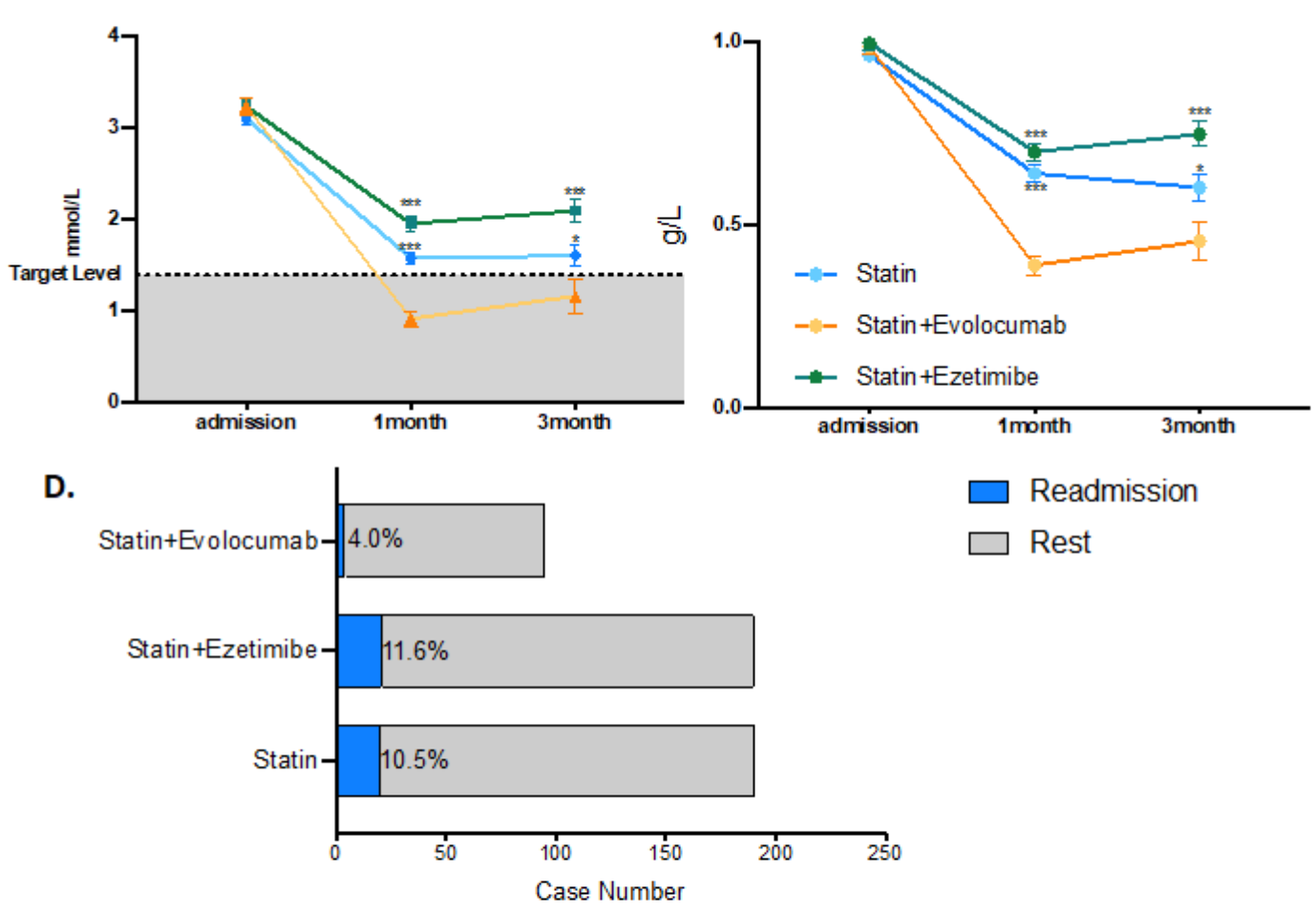

Statin+Evolocumab

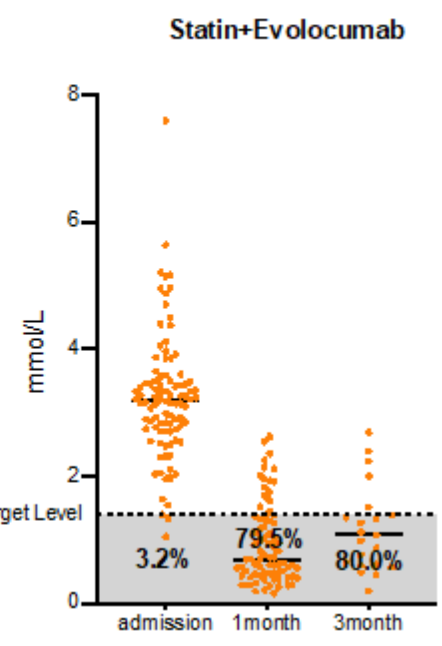

ApoB

Figure3. Lipid profile alterations and short-term follow-up among Statin plus Evolocumab / Statin/ Statin plus Ezetimibe lipid-lowering strategies in AMI patients after PSM adjustment.

(A). LDL level and compliance rate among different lipid-lowering strategies on admission and $1^{\text {st }}$ and $3^{\text {rd }}$ month follow-up. Each point represent one AMI patient's lipid data after PSM adjustment. LDL(B) and ApoB(C) alternation among different lipid-lowering strategies on admission and $1^{\text {st }}$ and $3^{\text {rd }}$ month follow-up. Data were shown in meantSEM. (D).Readmission rate among each group.

95 Statin plus Evolocumab users, 190 Statin plus Ezetimibe users and 190 statin users were chosen after 1:2:2 propensity score matching. For statistical analysis one-way ANOVA followed by Sidak's multiple comparison test was applied, *p < $0.05, * * * p<0.001$.

\section{Figure 3}

Please See image above for figure legend. 
A. Statin

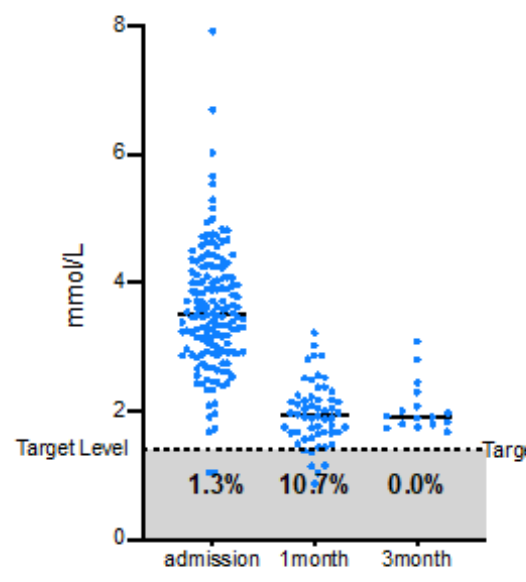

B.

LDL

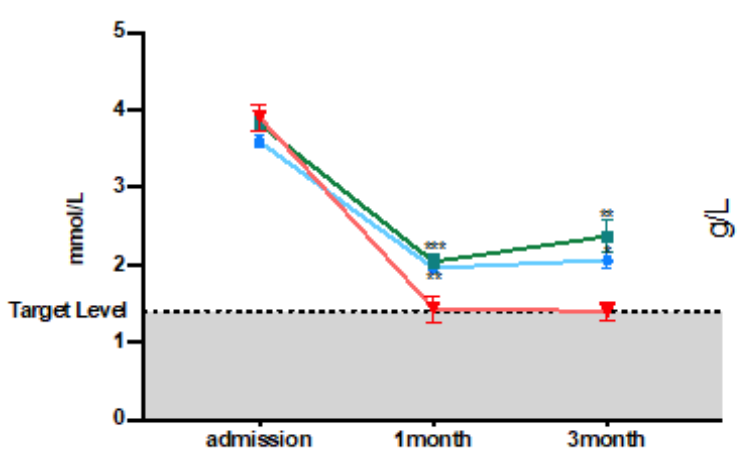

D.

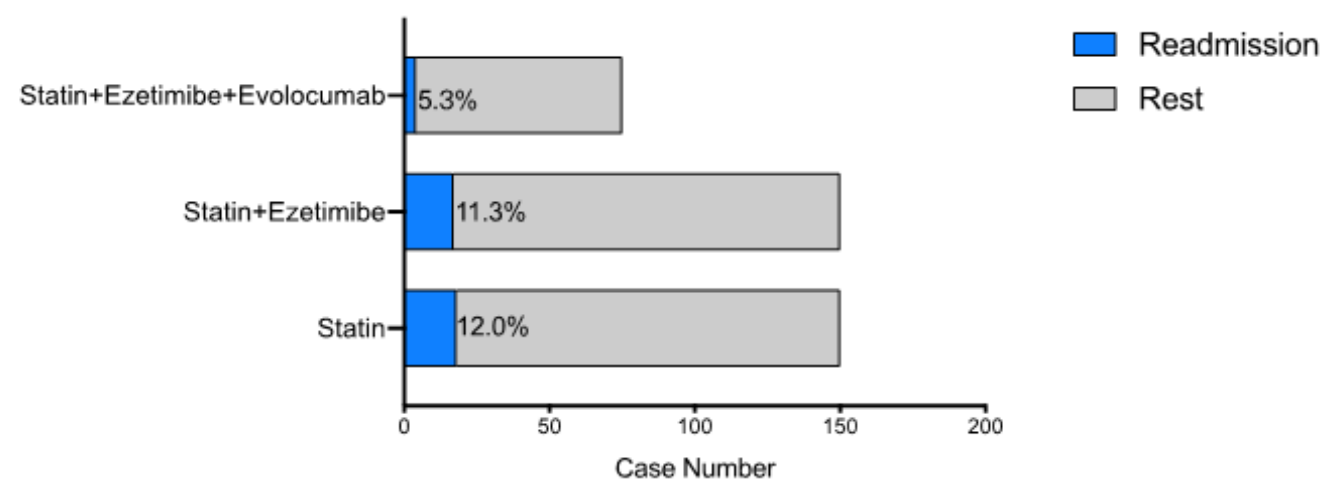

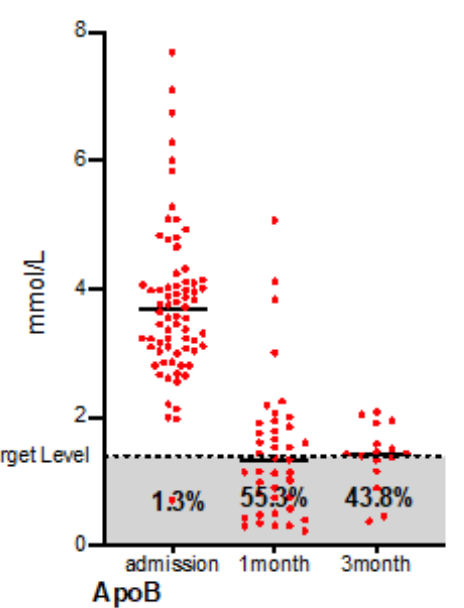

C.

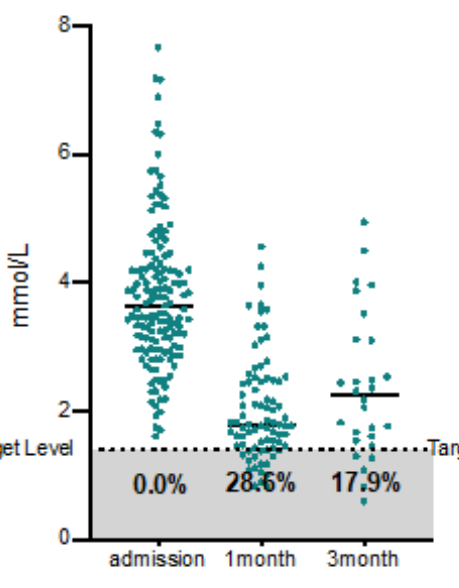

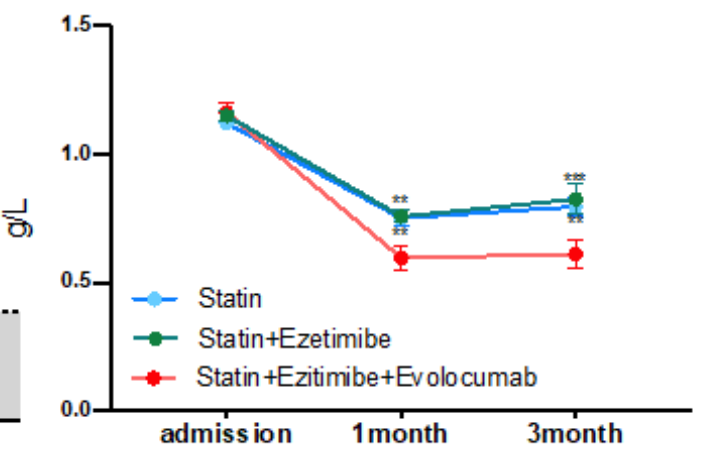

Figure4. Lipid profile alterations and short-term follow-up among Statin plus Ezetimibe plus Evolocumab / Statin/ Statin plus Ezetimibe lipid-lowering strategies in AMI patients after PSM adjustment.

(A). LDL level and compliance rate among different lipid-lowering strategies on admission and $1^{\text {st }}$ and $3^{\text {rd }}$ month follow-up. Each point represent one AMI patient's lipid data after PSM adjustment. $L D L(B)$ and $A p o B(C)$ alternation among different lipid-lowering strategies on admission and $1^{\text {st }}$ and $3^{\text {rd }}$ month follow-up. Data were shown in mean $\pm S E M$. (D).Readmission rate among each group. 75 Statin plus Ezetimibe plus Evolocumab users, 150 Statin plus Ezetimibe users and 150 statin users were chosen after 1:2:2 propensity score matching. For statistical analysis one-way ANOVA followed by Sidak's multiple comparison test was applied, " ${ }^{*}$ < $0.05,{ }^{* *} p<0.01,{ }^{* * *} p<0.001$.

\section{Figure 4}

Please See image above for figure legend.

\section{Supplementary Files}

This is a list of supplementary files associated with this preprint. Click to download. 
- Table.S2.docx

- Table.S1.docx

- Fig.S1.pdf

- Fig.S2.pdf

- GraphicalAbstarct.png 